\title{
ASSESSMENT OF FRICTION RESISTANCE OF FOUR ORTHODONTIC ARCH WIRES USING THREE LIGATION METHODS IN DRY AND WET CONDITIONS
}

\author{
Atia Abd Elwareth Abd Elrazik Yousif,* \\ Usama Mahmoud Abdel Karim ${ }^{\dagger}$
}

\section{ABSTRACT:}

Aim: Comparison of static and dynamic friction resistance of stainless steel (SS), nickel titanium ( $\mathcal{N} i T i$ ), titanium moly6denum alloy (TMMA) and copper nickel titanium (CuNiTi) archwires using three different methods of ligation; St St ligature, Slide low friction elastics and conventional elastics in both dry and wet conditions. Materials and Methods: 144 new orthodontic arch wires were divided according to the alloy type into four groups with 36 archwires for each; group 1: stainless steel (SS), group 2: nickel titanium ( $\mathcal{N} i T_{i}$ ), group 3: titanium molybdenum alloy (TSMA) and group 4: copper nickel titanium (CuNiTi). Each group was divided according to the method of ligation into three subgroups with 12 archwires for each; subgroup $\mathcal{A}$ : ligated with SS ligature, subgroup B: ligated with Slide low friction elastics and subgroup C: ligated with conventional elastics. Static and kinetic friction resistance was measured using Lloyd Instruments in both dry and wet conditions by adding artificial saliva. Student t-test, ANNOVA and LSD's test were used for statistical analysis. Significance level was set at $\mathbb{P} \leq 0.05$. Results: Student $t$-test showed static and kinetic friction for wet conditions were highly significant lower than dry conditions for the same arch wire/ligature cominations ( $P<=0.001)$. Static and Kinetic friction

\footnotetext{
* Lecturer of Orthodontic, Faculty of Dentistry, Tanta University, Egypt.

$\dagger$ Assistant Professor, Dental Biomaterial Department, Faculty of Dentistry, Tanta University, Egypt.
} 
Egyptian

Orthodontic Journal

resistance of SS archwires had significantly the least amount of friction followed 6y TMMA then $\mathcal{N} i T_{i}$ (Nitinol) and lastly CuNiTi. SS ligature exhibited significantly the least amount of friction followed by Slide low friction elastics while conventional elastics exhibited the greatest amount of friction $(\mathcal{P}<0.001)$. Conclusions: Wet conditions are essential for reducing friction in stainless steel bracket/archwire/ligature combinations. Stainless Steel archwire ligated to the SS bracket with SS ligatures exhibited the least amount of static and dynamic friction resistance followed by TMMA and then $\mathcal{N} i T_{i}$ and CuNiTi in an ascending order. SS ligature showed the least amount of friction followed by Slide elastomers and conventional elastic reported the highest friction resistance.

Keywords: Friction resistance, orthodontic arch wires, methods of ligature, wet versus dry condition.

\section{INTRODUCTION}

One important aim in orthodontics is to provide efficient tooth movement. The success of straight wire appliances relys on the ability of archwires to slide through brackets and tubes during leveling, aligning, space closing and canine retraction into an extraction site. Friction force generated at the bracket/arch wire interface tends to impede the desired movement and increases the anchorage strain ${ }^{(1)}$. High frictional forces affect treatment outcome and duration in a negative way ${ }^{(2)}$. Studies have shown that about $50 \%$ of the force necessary to initiate tooth movement is required to overcome friction resistance between brackets, arch wire and ligatures ${ }^{(3,4)}$. Ideally, frictional force should be kept to a minimum so that lower levels of force can be applied to obtain an optimal biological response for effective tooth movement ${ }^{(5)}$.

Kusy and Whitley ${ }^{(6)}$ partitioned the resistance to tooth movement into three separate components. The first component is classical friction that occurs between the wire and bracket surfaces and is further divided into static and kinetic friction. The second component is binding that 
Egyptian

Orthodontic Journal

occurs when a tooth is tipped or a wire is flexed so that the wire contacts the corner of the bracket. The third component is notching. Static friction is the force needed to start the motion of solid surfaces that were previously at rest with respect to each other. Kinetic friction is the force that resists the sliding motion of one solid object over another at a constant speed ${ }^{(7)}$.

In orthodontic sliding mechanics, the magnitude of friction is mainly determined by the material properties and surface characteristics of archwire, ligature of archwire to bracket including ligation technique and bracket ${ }^{(7,8-11)}$.

There are numbers of arch wire options available. The orthodontist should consider a variety of wire parameters and characteristics as necessary since no wire is appropriate for all treatment stages and no wire is ideal. Stainless steel wires were commonly used since they are inexpensive and had improved mechanical properties. Cobalt-chromium, nickel-titanium, titanium molybdenum alloy (beta-titanium) and multistranded stainless steel wires have been developed with extensive range of properties due to the advancements in the recent technology.

Straight-line traction with nonbinding sliding as shown in zero tip and torque brackets has demonstrated that frictional resistance generally increases respectively with arch wire selections of stainless steel, cobaltchromium, nickel-titanium, and beta titanium ${ }^{(12)}$. Interestingly, arch wire alloys of stainless steel, cobalt chromium, nickel-titanium, and beta titanium have increasing surface roughness characteristics in ascending order, which is believed to create higher frictional resistance ${ }^{(13)}$.

The method of ligation is an important contributor to the frictional force generated at the bracket/archwire interface. Traditionally ligatures were made of stainless steel, however due to the length of time these ligatures take to place, low friction unconventional elastomeric ligatures were manufactured and gained acceptance in orthodontics due to their ability to quickly stretch over the bracket, thereby decreasing chair time and increasing patient comfort. There are contradictory results about friction forces of different ligations. Many studies reported that elastomeric ligatures produce greater friction resistance than stainless 
steel ligature ${ }^{(3,11,14-20)}$. On the other hand, Natt et. al., ${ }^{(21)}$ reported that stainless steel ligatures produce greater frictional resistance than elastomeric ligations, while Cordasco et. al., ${ }^{(22)}$ reported that no significant differences of frictional forces were found when comparing metallic and elastic ligation.

Moreover, many studies reported that artificial saliva reduces friction ${ }^{(11,22-24)}$. On the other hand, several studies reported that the use of artificial saliva acts as an adhesive and increases friction ${ }^{(3,16,21)}$, while other studies showed that saliva makes no difference on the effect of friction ${ }^{(25-27)}$.

Static and kinetic friction resistance of Stainless steel, nickel titanium, titanium molybdenum alloy and copper nickel titanium archwires using three methods of ligation were tested in dry and wet conditions in order to provide the best archwire/ligature combination that offers the least friction during sliding mechanics.

\section{MATERIALS AND METHODS}

In this study, 144 new straight part of orthodontic 0.016 " $\times 0.022$ " archwires (8 cm length) were divided according to the alloy type into four groups with 36 archwires for each; group 1: stainless steel ${ }^{\ddagger}$ (SS), group 2: nickel titanium ${ }^{\S}$ (NiTi), group 3: titanium molybdenum alloy ${ }^{* *}$ (TMA) and group 4: copper nickel titanium ${ }^{\dagger \dagger}$ (CuNiTi ). Each group was divided according to the method of ligation (figure 1) into three subgroups with 12 archwires for each; subgroup A: ligated with SS ligature ${ }^{*}$, subgroup B: ligated with Slide low friction elastics ${ }^{\S \S}$ and subgroup C: ligated with conventional elastics. ${ }^{* * *}$ Static and kinetic friction resistance was measured using Lloyd Instrument ${ }^{\dagger \dagger \dagger}$ in both dry and wet conditions by adding artificial saliva.

* Ormco part no. 211-0701 lot:021002377.Ormco Glendora, California 91740-5339

$\S$ Ormco part no. 211-0502 lot:021414200 Ormco Glendora, California 91740-5339

** Ormco part no. 210-1402 lot:041590408.Ormco Glendora, California 91740-5339

†† Ormco part no. 210-9103 lot:121366438.Ormco Glendora, California 91740-5339

\# 3M Unitek, Rd, Monrovia, CA.

$\S \S$ Slide low friction elastics.k6224-10 Leone s.p.a.lot no14021701 Orthodontic Products, Italy.

*** American orthodontics. Conventional elastics. WA. US

t†† Lloyd Instrument Ltd, UK Lloyd. 


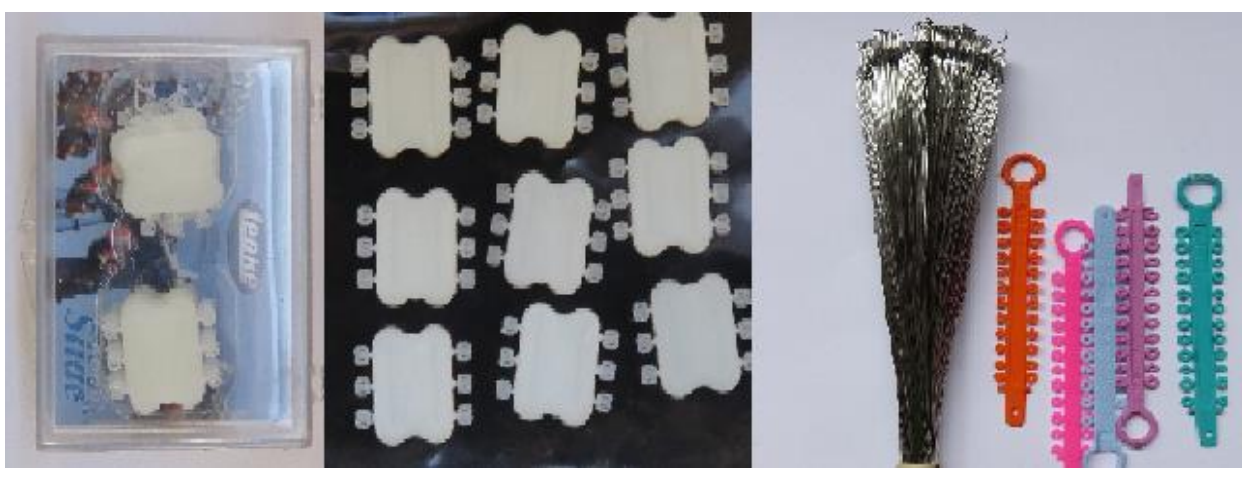

Figure (1): Shows slide low friction elastics, SS ligature wire and conventional elastics.

\section{Fabrication of the Support for the Friction Test:}

The stainless steel brackets ${ }^{\dagger+}$ used in this study had a 0.022-inch slot, zero degree torque and tip. Rectangular acrylic plates $(14 \mathrm{~cm}$ long by $4 \mathrm{~cm}$ wide by $1 \mathrm{~cm}$ thick) with four projections were fabricated to bond 4 brackets in straight line with $8 \mathrm{~mm}$ distance between each 2 brackets (Figure 2). The determined bracket bonding area of the acrylic plate was abraded with 120 grit abrasive paper (Buehler, Lake Bluff, IL, USA) before the application of chemically activated Orthodontic Concise adhesive (3M Unitek Corporation, Monrovia, CA). Before resin polymerization occurred, a stainless steel wire $(0.016 " \times 0.022$ ") was used to align the brackets to ensure a straight archwire to be passively centered in all of the bracket slots and removed after polymerization. Each archwire was ligated to 4 brackets. For each specimen a new archwire and a new ligature were used. In an attempt to standardize SS ligature placement, a previously described technique by Bazakidou et al was used ${ }^{(27)}$. SS ligature was initially fully tightened and then unwound to allow little play between both spans of ligature and the archwire. The elastomeric ligatures Slide low friction and conventional elastics were inserted in the conventional mode with the elastic tie applicator (ligature

\# Brackets Mini Standard Edgewise, American orthodontics, WA., USA. 
Egyptian

Orthodontic Journal

gun (Straight-shooter) that allowed the elastomeric modules to be stretched by a standard amount prior to placement embracing the mesial and distal winglets of the brackets.

\section{Friction resistance testing:}

Prior to testing, all brackets and archwires were cleaned with 95\% ethanol. Friction resistance was measured by Lloyd Instrument with a cross head speed of $5 \mathrm{~mm} / \mathrm{min}$ (figure 2). The archwire must lie passively in all brackets before wire ligation. The Lloyd Instrument was started to move $1 \mathrm{~mm}$ and if the measurement was less than $1 \mathrm{gm}$ the system was considered passive, if the machine recorded more than $1 \mathrm{gm}$, adjustment and re-bonding new brackets until the system become completely passive before wire ligation. A $10 \mathrm{~cm}$ straight segment of the archwire to be tested was ligated with the ligature to be tested and the machine was allowed to move for $3 \mathrm{~cm}$ distance.

The initial resistance to the sliding which determines the force needed to initiate movement was recorded as static frictional resistance and the peak force during movement was recorded as kinetic frictional resistance. This experiment was repeated 24 times (12 dry and 12 wet conditions) for each subgroup using new brackets, new wires, and new ligature. In wet condition brackets, wires and ligatures were soaked in artificial saliva for 24 hour at $37^{\circ} \mathrm{C}$ and artificial saliva was dripped from a plastic syringe onto the ligated wire at the bracket at a rate of 1 $\mathrm{ml} /$ minute before (and during) testing. Artificial saliva was prepared according to the formula of Macknight-Hane and Whitford ${ }^{(28)}$.

Data was collected and statistical analysis was performed using IBM SPSS 20 software for windows (Armonk, NY, USA). Student $t$-test was used to compare between wet and dry condition for the same archwire/ligature combination. Two ways ANOVA was used to determine the variance in between the different groups. LSD's test was used for pair-wise comparisons. The significance level was set at $\mathrm{P} \leq 0.05$. 


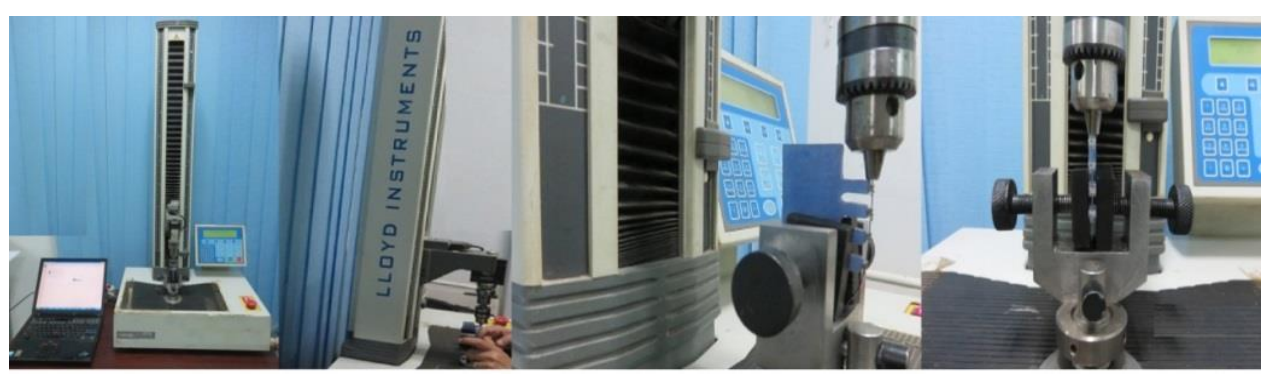

Figure (2): Friction testing using Lloyd Instrument Ltd.

\section{RESULTS}

Means and standard deviation of friction resistance for dry and wet conditions are presented in table 1. Student $t$-test (table 1) showed static and kinetic friction for wet conditions were highly significant lower than dry conditions for the same archwire/ligature combination $(\mathrm{P}<0.001)$. Two way ANOVA for Static (table 2) and kinetic (table 4) friction resistance of wet condition showed a highly significance difference $(\mathrm{P}<0.001)$ between archwires, between ligature methods and a significant archwire/ligature method interaction. Pair-wise comparison test showed SS arch wires had significantly $(\mathrm{P}<0.001)$ the least amount of static (table 3) and kinetic (table 5) friction followed by TMA then NiTi (Nitinol) and lastly CuNiTi. For all wires used in this study SS ligature showed significantly $(\mathrm{P}<0.001)$ the lowest value for static and kinetic friction resistance followed by slide low friction elastics and conventional elastic ligatures recorded significantly $(\mathrm{P}<0.001)$ the highest value of friction resistance. The SS arch wire with SS ligature showed the least amount of friction followed by TMA wire with SS ligature then NiTi wire with SS ligature and the highest friction resistance was recorded by CuNiTi wire ligated by conventional elastic ligature. 
Table (1): shows means \pm SD in grams and Student $t$-test of dry versus wet conditions for static and kinetic friction resistance for the same arch wire / ligature method combinations.

\begin{tabular}{|c|c|c|c|c|c|c|}
\hline \multirow{3}{*}{$\begin{array}{l}\text { Methods of } \\
\text { Ligature }\end{array}$} & \multicolumn{5}{|c|}{ Type of arch wire alloy } & \\
\hline & \multicolumn{3}{|c|}{ Static } & \multicolumn{3}{|c|}{ Kinetic } \\
\hline & dry & wet & $\mathbf{P}$ & dry & wet & $\mathbf{P}$ \\
\hline \multicolumn{7}{|l|}{ St St archwire } \\
\hline St St & $83.48 \pm 1.11$ & $54.43 \pm 1.23$ & $<0.001 *$ & $120.19 \pm 1.08$ & $95.96 \pm 1.02$ & $<0.001 *$ \\
\hline Slide & $94.53 \pm 1.85$ & $76.21 \pm 0.68$ & $<0.001 *$ & $127.65 \pm 1.23$ & $107.19 \pm 0.82$ & $<0.001 *$ \\
\hline Conventional & $124.48 \pm 1.39$ & $92.52 \pm 1.24$ & $<0.001 *$ & $167.80 \pm 1.60$ & $125.73 \pm 1.10$ & $<0.001 *$ \\
\hline \multicolumn{7}{|l|}{ NiTi archwire } \\
\hline St St & $124.05 \pm 1.69$ & $83.31 \pm 1.26$ & $<0.001 *$ & $159.24 \pm 1.16$ & $115.46 \pm 0.98$ & $<0.001 *$ \\
\hline Slide & $138.92 \pm 1.12$ & $108.53 \pm 0.85$ & $<0.001^{*}$ & $172.46 \pm 0.96$ & $160.76 \pm 0.61$ & $<0.001 *$ \\
\hline Conventional & $167.36 \pm 2.79$ & $121.12 \pm 0.85$ & $<0.001 *$ & $196.20 \pm 0.99$ & $171.36 \pm 1.04$ & $<0.001 *$ \\
\hline \multicolumn{7}{|l|}{ TMA archwire } \\
\hline St St & $111.69 \pm 0.85$ & $75.55 \pm 1.09$ & $<0.001 *$ & $146.22 \pm 0.67$ & $99.18 \pm 0.60$ & $<0.001 *$ \\
\hline Slide & $125.67 \pm 0.92$ & $98.12 \pm 0.85$ & $<0.001^{*}$ & $160.51 \pm 0.62$ & $138.40 \pm 7.93$ & $<0.001 *$ \\
\hline Conventional & $155.07 \pm 0.71$ & $115.06 \pm 0.58$ & $<0.001 *$ & $185.72 \pm 0.81$ & $153.14 \pm 0.89$ & $<0.001 *$ \\
\hline \multicolumn{7}{|c|}{ CuNiTi archwire } \\
\hline St St & $147.29 \pm 0.96$ & $97.28 \pm 0.73$ & $<0.001^{*}$ & $174.68 \pm 0.62$ & $126.22 \pm 0.93$ & $<0.001 *$ \\
\hline Slide & $179.39 \pm 1.05$ & $123.60 \pm 0.67$ & $<0.001 *$ & $189.41 \pm 0.98$ & $163.37 \pm 0.88$ & $<0.001 *$ \\
\hline Conventional & $180.13 \pm 0.806$ & $134.42 \pm 0.65$ & $<0.001 *$ & $208.73 \pm 1.58$ & $182.67 \pm 0.84$ & $<0.001 *$ \\
\hline
\end{tabular}

Table (2): shows two ways ANOVA of static friction resistance of wet condition

\begin{tabular}{|l|c|c|c|c|c|}
\hline & $\begin{array}{c}\text { Sum of } \\
\text { squares }\end{array}$ & $\begin{array}{c}\text { Degrees of } \\
\text { freedom }\end{array}$ & $\begin{array}{c}\text { Means square of } \\
\text { error }\end{array}$ & F-value & P-value \\
\hline $\begin{array}{l}\text { Type of } \\
\text { arch wire }\end{array}$ & 30433.334 & 3 & 526.874 & 24.099 & $<0.001 *$ \\
\hline $\begin{array}{l}\text { Ligature } \\
\text { methods }\end{array}$ & 29715.91 & 2 & 436.854 & 45.358 & $<0.001 *$ \\
\hline Interaction & 47589.07 & 5 & 685.967 & 96.126 & $<0.001^{*}$ \\
\hline
\end{tabular}

*: highly significantly different at $\mathrm{p}<0.001$ 
Egyptian

Orthodontic Journal

Table (3): Shows LSD's pair-wise comparisons test of static friction resistance means \pm SD in grams for different archwires /ligature methods combinations in wet condition

\begin{tabular}{|l|c|c|c|c|}
\hline \multicolumn{5}{|c|}{ Arch wire } \\
\hline Ligature method & St St & NiTi & TMA & CuNiTi \\
\hline St St & $54.43 \pm 1.23^{\mathrm{a}}$ & $83.31 \pm 1.26^{\mathrm{d}}$ & $75.55 \pm 1.09^{\mathrm{b}}$ & $97.28 \pm 0.73^{\mathrm{g}}$ \\
\hline Slide & $76.21 \pm 0.68^{\mathrm{b}}$ & $108.53 \pm 0.85^{\mathrm{e}}$ & $98.12 \pm 0.85^{\mathrm{g}}$ & $123.60 \pm 0.67^{\mathrm{i}}$ \\
\hline Conventional & $92.52 \pm 1.24^{\mathrm{c}}$ & $121.12 \pm 0.85^{\mathrm{f}}$ & $115.06 \pm 0.58^{\mathrm{h}}$ & $134.42 \pm 0.65^{\mathrm{j}}$ \\
\hline
\end{tabular}

Means with different letters are significantly different at $\mathrm{p} \leq 0.05$

Table (4): shows two ways ANOVA of static friction resistance of wet condition

\begin{tabular}{|l|c|c|c|c|c|}
\hline & $\begin{array}{c}\text { Sum of } \\
\text { squares }\end{array}$ & $\begin{array}{c}\text { Degrees of } \\
\text { freedom }\end{array}$ & $\begin{array}{c}\text { Means square } \\
\text { of error }\end{array}$ & F-value & P-value \\
\hline Type of arch wire & 41035.93 & 3 & 695.642 & 19.663 & $<0.001^{*}$ \\
\hline Ligature methods & 49847.03 & 2 & 584.716 & 35.828 & $<0.001^{*}$ \\
\hline Interaction & 58962.57 & 5 & 743.659 & 101.126 & $<0.001 *$ \\
\hline
\end{tabular}

*: highly significantly different at $\mathrm{p}<0.001$

Table (5): shows LSD's pair-wise comparisons test of kinetic friction resistance means \pm standard deviation in grams for different archwires / ligature combinations in wet condition.

\begin{tabular}{|l|c|c|c|c|}
\hline & \multicolumn{4}{|c|}{ Arch wire } \\
\hline $\begin{array}{c}\text { Ligature } \\
\text { method }\end{array}$ & SS & NITI & TMA & Cu Ni Ti \\
\hline St st & $95.96 \pm 1.02^{\mathrm{a}}$ & $115.46 \pm 0.98^{\mathrm{d}}$ & $99.18 \pm 0.60^{\mathrm{g}}$ & $126.22 \pm 0.93^{\mathrm{c}}$ \\
\hline Slide & $107.19 \pm 0.82^{\mathrm{b}}$ & $160.76 \pm 0.61^{\mathrm{e}}$ & $138.40 \pm 7.93^{\mathrm{h}}$ & $163.37 \pm 0.88^{\mathrm{j}}$ \\
\hline Conventional & $125.73 \pm 1.10^{\mathrm{c}}$ & $171.36 \pm 1.04^{\mathrm{f}}$ & $153.14 \pm 0.89^{\mathrm{i}}$ & $182.67 \pm 0.84^{\mathrm{k}}$ \\
\hline
\end{tabular}

Means with different letters are significantly different at $p<0.05$

Volume 50-December 2016 
Egyptian

Orthodontic Journal

\section{DISCUSSION}

Some factors have been attributed to the increase in friction in orthodontic systems, including the alloy of which the wire is made, the material of the bracket channel, lubrication and the method of ligation $^{(1,18)}$. The brackets in this study were chosen to be conventional stainless steel with zero degrees of tip and torque and arranged in straight line to allow the only friction present to be classical friction and not due to binding or notching. Similarly, $0.016 " \times 0.022$ " arch wires size was kept constant to allow arch wire material type and the ligature method to be the two variables to be tested besides dry versus wet condition. In an effort to be as accurate as possible, a new bracket, archwire and ligature were used for each specimen to avoid bias due to repeated use and the archwires were tested to be passively placed in the brackets before ligature application. These standardizations are reflected by the small standard deviations for all subgroups in the results of this study.

The result of the present study showed that stainless steel arch wire material provide the lowest friction resistance in wet condition followed by titanium molybdenum alloy ( $\beta$-titanium TMA), then Nitinol (NiTi), and copper nickel titanium $(\mathrm{Cu} \mathrm{Ni} \mathrm{Ti})$ which reported the highest friction resistance. Many studies ${ }^{(14,29-41)}$ reported the superiority of stainless steel archwires as it was associated with the least amount of friction but followed by $\mathrm{Ni} \mathrm{Ti}$ while beta titanium exhibited the highest frictional resistance. This was explained by the increased surface roughness of $\beta$-titanium wire as compared with stainless steel arch wire ${ }^{(7-42)}$ as reported by scanning electron microscope and laser spectroscopic picture $^{(26,43)}$. Other researchers ${ }^{(8,14,43)}$ concluded the main reason of the increase in friction of $\beta$-titanium wire is attributed to the adherence of the wire material to the surface of the bracket slot during sliding. Low stiffness of $\beta$-titanium causes high flexing of archwire and subsequently high friction ${ }^{(37,42,44,45)}$.

In our study TMA archwires have friction resistance lower than that of NiTi arch wires. The TMA wire used in this study has low surface roughness which described a low friction type TMA wire as claimed by the manufacturer. In agreement with the present study, Kapila et. al., ${ }^{(46)}$ 
Egyptian

Orthodontic Journal

reported that the friction developed at bracket-wire interface is more with Nitinol wires followed by beta-titanium and then stainless steel wires

In the present study the greatest friction resistance was reported for CuNiTi archwires. Studies ${ }^{(47,48)}$ showed that CuNiTi wires presented the greatest wire-surface roughness and proved that CuNiTi $35^{\circ} \mathrm{C}$ has not only very visible drawing marks and slots, but also micro-cavities formed due to pullout of particles of $\mathrm{NiTi}$, which could generate a higher coefficient of attrition.

The technological advancement of elastic materials has increased their applicability in contemporary orthodontic treatments. Ligatures with polymer coating have been introduced in order to reduce the friction caused in the bracket/ archwire/ligature set. Manipulation and placement of elastic ligature consumes less chair side time than that of using stainless steel ligature ${ }^{(31)}$. The result of this study showed that all combinations of stainless steel bracket and different archwires under dry and wet conditions showed more friction forces with elastic ligatures when compared to stainless steel ligature wire. This is supported by a wide spread agreement in the orthodontic literature ${ }^{(3,12,14,20)}$.

The reasons reported in the literature that make elastic ligatures more friction generator, first is the force exerted on the arch wire by the elastic ligature when stretched over the brackets wings is very much greater than that for the loosely ligatured stainless steel ligature, and second is the coefficient of friction between elastic material and stainless steel sliding surfaces is much greater than that between two stainless steel surfaces in contact which have the same friction coefficient. Besides, the surface characteristics of the modules may have a greater effect on friction ${ }^{(15,16,49,50)}$.

In disagreement with the result of this study, Natt et. al., ${ }^{(21)}$ reported that stainless steel ligatures showed the highest mean static frictional forces compared to elastomeric ligations (Alastik Easy to Tie modules, Super Slick Mini Stix elastomeric modules, Power "O" modules). This finding could be attributed to the tight ligation by the stainless steel 
Egyptian

Orthodontic Journal

ligatures with the wire which will exceed that of the elastic ligature and might reach to complete locking of the arch wire to the bracket ${ }^{(12,21)}$. While Cordasco et. al., ${ }^{(22)}$ reported that there is no significant differences of frictional forces were found when comparing metallic and elastic ligation. This controversy is further clarified by that, whether the stainless steel ligature wire is tight or loosely ligated. The force produced by ligature wires is sensitive to the method used to apply the ligatures and may vary from zero to extremely high levels ${ }^{(51)}$. Moreover, Iwasaki et. al., ${ }^{(19)}$ found that loose stainless steel ligation was not associated with lower frictional forces than tight stainless steel ligation. A possible explanation is that once the archwire begins to slide, the SS ligature may loosen slightly, unbind, and the friction will substantially be reduced.

The result of the present study showed that Slide elastomeric ligature is able to reduce frictional forces significantly with respect to conventional elastomeric ligatures. Previous in vitro studies ${ }^{(52,53)}$ agreed with the present study. This was attributed to that the Slide elastomers offer more freedom of sliding to the archwire than conventional elastics (52) and the incomplete contact between the Slide module and the archwire may allow easier sliding ${ }^{(16)}$.

According to this study, static and kinetic friction resistance in dry condition are significantly higher than in wet condition with artificial saliva for the same archwire/ ligature combinations $(\mathrm{P}<0.001)$. This is supported by the finding of many studies that reported artificial saliva reduces friction ${ }^{(11,20,22-24)}$. On the other hand, several studies reported that the use of artificial saliva acts as an adhesive and increases friction ${ }^{(3,16,21)}$, while other studies ${ }^{(26-27)}$ showed that saliva makes no difference on the effect of friction. Jones and Ben Bihi ${ }^{(27)}$ reported that the artificial saliva had no effect on the friction for Slide ligature and conventional elastomeric modules. These differences could be attributed to differences in methodology, saliva composition and storage time. In the present study, the assembly was soaked in artificial saliva for 24 hours and it was dripped with saliva during testing. Hain et. al., ${ }^{(53)}$ found that conventional ligatures showed a significant reduction in friction after one week of saliva exposure compared to 60 minutes of saliva exposure. 
Egyptian

Orthodontic Journal

When comparing Super Slick ligatures that have been soaked in saliva for 60 minutes, they showed significantly less friction than those that have been given just one drop of saliva prior to testing. This supports that the presence of saliva for suitable time is a necessary component for making these ligatures perform correctly. Khambay ${ }^{(17)}$ did not find that Super Slick demonstrated lower levels of friction compared to conventional and stainless steel ligatures, however the ligatures were dropped with saliva only during testing and were not soaked for any length of time.

\section{CONCLUSIONS}

1. Stainless steel archwires offered less friction followed by TMA, then $\mathrm{NiTi}$ and $\mathrm{CuNi} \mathrm{Ti}$ archwires.

2. Among ligation methods, stainless steel offered the least friction followed by Slide ligatures, and then conventional elastics.

3. Wet conditions are essential for reducing friction in stainless steel bracket / archwire / ligature combinations.

\section{REFERENCES}

1. Griffth HS, Sherrif M, Ireland AJ. "Resistance to sliding with three types of elastomeric modules," Am J Orthod Dentofac Orthop. 2005;127:670-5.

2. Rossouw PE. Friction: An Overview. Seminar Orthod. 2003; 9: 218-22.

3. Husain N, Kumar A. Frictional resistance between orthodontic brackets and archwire: an in vitro study. J Contemp Dent Pract. 2011; 12: 91-9.

4. Profitt WR. Contemporary Orthodontics, 2nd edn. St. Louis: CV Mosby; 2000.

5. Chimenti C, Franchi L, Di Giuseppa MG, Lucci M. Friction of orthodontic elasto-meric ligature with different diameters. Angle Orthod. 2004; 75: 377-81.

6. Kusy RP, Whitley JQ. Influence of archwire and bracket dimensions on sliding mechanics: derivations and determinations of the critical contact angles for binding. Eur J Orthod 1999; 21:199-208. 
7. Burrow JS, Charlotte NC. Friction and resistance to sliding in orthodontics: A critical review. Am J Orthod Dentofac Orthop. 2009; 135: 442-7.

8. Tecco S, Festa F, Caputi S, Traini T, Di Lorio D, D'Attilio M. Friction of conventional and self-ligating brackets using a 10 bracket model. Angle Orthod. 2004; 75: 828-32.

9. Cacciafesta V, Sfondrini M F, Scribante A, Klersy C, Auricchio F. Evaluation of friction of conventional and metal-insert ceramic brackets in various bracket-archwire combinations. Am J Orthod Dentofac Orthop. 2003; 124: 403-9.

10. Thorstenson G A , Kusy R P. Resistance to sliding of self-ligating brackets versus conventional stainless steel twin brackets with second order angulation in the dry and wet (saliva) states. Am J Orthod Dentofac Orthop. 2001; 120: 361-70.

11. Park JH, Lee YK, Lim BS, Kim CW. Frictional forces between lingual brackets and archwires measured by a friction tester. Angle Orthod. 2004; 74: 816-24.

12. Mendes K, Rossouw PE. Friction: Validation of manufacturer's claim. Seminar Orthod. 2003; 9: 236-50.

13. Smith DV, Rossouw PE, Watson P. Quantified simulation of canine retraction: evaluation of frictional resistance. Seminar Orthod. 2003; 9: 262-80.

14. Obaidi HA, Al-Mukhatr AM. The Influence of Different Ligature Materials on Frictional Coefficient of Slided Bracket on Arch Wire. Al-Rafidain Dent J. 2009; 9: 199-202.

15. Gandini P, Orsi L, Bertoncini C, Massironi S, Franchi L. In vitro frictional forces generated by three different ligation methods. Angle Orthod. 2008; 78: 917-21.

16. Khambay B, Millett D, McHugh S. Archwire seating forces produced by different ligation methods and their effect on frictional resistance. Eu J Orthod. 2005; 27: 302-8. 
Egyptian

Orthodontic Journal

17. Khambay B, Millett D, McHugh S. Evaluation of methods of archwire ligation on frictional resistance. Eur J Orthod. 2004; 26: 327-32.

18. Hain M, Dhopatkar A, Rock P. The effect of ligation method on friction in sliding mechanics. Am J Orthod Dentofac Orthop. 2003; 123: 416-22.

19. Iwasaki LR, Beatty MW, Randall C, Nickel JC. Clinical ligation forces and intraoral friction during sliding on a stainless steel archwire. Am J Orthod Dentofac Orthop. 2003; 123: 408-15.

20. Thorstenson GA, Kusy RP. Effects of ligation type and method on the resistance to sliding of novel orthodontic brackets with second-order angulation in the dry and wet states. Angle Orthod. 2003; 73: 418-30.

21. Natt AS, Sekhon AK, Munjal S, Duggal R, Holla A, Gupta P, Gandhi P, Sarin S. A Comparative Evaluation of Static Frictional Resistance Using Various Methods of Ligation at Different Time Intervals: An In Vitro Study Inter J Dent. 2015; Article ID 407361: 1-7.

22. Cordasco G, Farronato G, Festa F, Nucera R, Parazzoli E, Grossh GB. In vitro evaluation of the frictional forces between brackets and archwire with three passive self-ligating brackets. Eur J Orthod. 2009; 31: 643-6.

23. Karamouzos A, Athanasiou AE, Papadopoulos MA. Clinical characteristics and properties of ceramic brackets: a comprehensive review. Am J Orthod Dentofac Orthop. 1997; 112: 34-40.

24. Tanne K, Matsubara S, Hotei Y, Sakuda M, Yoshida M. Frictional forces and surface topography of a new ceramic bracket. Am J Orthod Dentofac Orthop. 1994;106: 273-8.

25. Kusy RP, Whitley JQ, Prewitt MJ. Comparison of the frictional coefficients for selected archwire-bracket slot combinations in the dry and wet states. Angle Orthod. 1991; 61: 293-302.

26. Jones SP, Ben Bihi S. Static frictional resistance with the slide low-friction elastomeric ligature system. Aust Ortho J. 2009; 25: 136-41. 
Egyptian

Orthodontic Journal

27. Bazakidou E, Nanda R S, Duncanson Jr M G, Sinha P 1997 Evaluation of frictional resistance in esthetic brackets. Am $\mathrm{J}$ of Orthod Dentofac Orthop. 112: 138-44.

28. McKnight-Hanes C1, Whitford GM. Fluoride release from three glass ionomer materials and the effects of varnishing with or without finishing. Caries Res. 1992; 26: 345-50.

29. Verstrynge A, Van Humbeeck J, Willems G. In-vitro evaluation of the material characteristics of stainless steel and beta-titanium orthodontic wires. Am J Orthod Dentofac Orthop 2006; 130: 460-70.

30. Vinay K, Venkatesh MJ, Nayak RS, Pasha A, Rajesh M, Kumar P. A comparative study to evaluate the effects of ligation methods on friction in sliding mechanics using 0.022 " slot brackets in dry state: An In-vitro study. J Int Oral Health 2014; 6: 76-83.

31. Mirzaie M, Arash V, Rabiee, RamezaniI Bijani A. Evaluation of frictional resistance between monocrystalline (ICE) brackets and Stainless Steel, Beta TMA and NiTi arch wires. Caspian J Dent Res. 2013; 2: 23-28.

32. Yu JH, Wu LC, Hsu JT, Chang YY, Huang HH, Huang HL. Surface Roughness and topography of four commonly used typed of orthodontic Archwires. J Med Biol Eng. 2011; 31: 367-70.

33. Fidalgo TKdS, Pithon MM, Maciel JVB, Bolognese AM. Friction between different wire bracket combinations in an artificial saliva-an in vitro study. J Appl Sci. 2011; 19(1): 57-62.

34. Dilip S, Krishnaraj R, Rajasekar, Duraisamy S, Poornima R. A Comparative study of frictional resistance of stainless steel,nickel titanium,and CNA archwires with stainless steel brackets-an in vitro study. SRM U J Dent Sci 2010; 1: 63-7.

35. Vijayalakshmi R D, Nagachandran K S, Kummi P, Jayakumar P. A comparative evaluation of metallurgical properties of stainless steel and TMA archwires with timolium and titanium niobium archwires - An in vitro study. Indian J Dent Res. 2009; 20: 448-52. 
Egyptian

Orthodontic Journal

36. Claro CA, Abrlo J, Reis SA. Forces in stainless steel, TiMolium and TMA intrusion arches, with different bending magnitudes. Braz Oral Res. 2007; 21: 140-5.

37. Nishio C, Motta AF, Elias CN, Mucha JN. In vitro evaluation of frictional forces between archwires and ceramic brackets. Am J Orthod Dentofac Orthop. 2004; 125: 56-64.

38. Cash A, Curtis R, Garrigia D, McDonald F. A comparative study of the static and kinetic frictional resistance of titanium molybdenum alloy archwires in stainless steel brackets. Eu J Orthod. 2004; 26: 105-11.

39. Kusy RP, Whitley JQ, Gurgel JA. Comparisons of surface roughness and sliding resistance of 6 titanium based or TMA- type arch wires. Am J Orthod Dentofac Orthop. 2004; 126: 589-603.

40. Cacciafesta V, Francesca M, Ricciardi A, Scribante A, Klersy C, Auricchio F. Evaluation of friction of stainless steel and esthetic selfligating bracket in various bracket-archwire combinations. Am J Orthod Dentofac Orthop. 2003; 124: 395-402.

41. Krishnan V, Kumar KJ. Mechanical properties and surface characteristics of three archwire alloys. Angle Orthod. 2004; 74: 825-31.

42. Wichelhous A, Hibst R, Sander FG. The effect of surface treatment and clinical use on friction in NiTi orthodontic wires. J Dental Materials. 2005; 21: 938-45.

43. Thorstenson GA, Kusy RP. Effect of archwire size and material on the resistance to sliding of self-ligating brackets with second-order angulation in the dry state. Am J Orthod Dentofac Orthop. 2002; 122: 295-305.

44. Hayashi K, Araki Y, Mizoguchi I. Nonli-near Large-Deflection Analysis of Ortho-dontic Wires. Angle Orthod. 2004; 74: 112-17.

45. Kapila S, Angolkar PV, Duncanson MG, Nanda RS. Evaluation of friction between edgewise stainless steel brackets and orthodontic wires of four alloys. Am J Orthod Dentofacial Orthop.1990; 98: 117-26. 
Egyptian

Orthodontic Journal

46. Gravina MA, Canavarro C, Elias CN. Mechanical properties of NiTi and $\mathrm{CuNiTi}$ wires used in orthodontic treatment. Part 2: Microscopic surface appraisal and metallurgical characteristics. Dental Press J Orthod. 2014 Jan-Feb; 19: 69-76.

47. Fischer-Brandies H, Es-Souni M, Kock N, Raetzke K, Bock O. Transformation behavior, chemical composition, surface topography and bending properties of five selected 0.016" X 0.022" NiTi archwires. J Orofac Orthop. 2003; 64: 88-99.

48. Baccetti T, Franchi L, Camporesi M, Defraia E, Barbato E. Forces produced by different nonconventional bracket or ligature systems during alignment of apically displaced teeth. Angle Orthod. 2009; 79: 533-9.

49. Von Fraunhofer JA, Bonds PW, Johnson BE. Force generation by orthodontic coil springs. Angle Orthod. 1993; 63: 145-15.

50. Harradine NW. Self-legating brackets: where are we now? J Orthod. 2003; 30: 262-73

51. Franchi L, Baccetti T. Forces released during alignment with a preadjusted appliance with different types of elastomeric ligatures. Am J Orthod Dentofac Orthop. 2006; 129: 687-90.

52. Fortini A, Lupoli M, Cacciafesta V. A new low-friction ligation system. J Clin Orthod. 2005; 39: 464-70.

53. Hain M, Dhopatkar A, Rock P. A comparison of different ligation methods on friction. Am J Orthod Dentofac Orthop. 2006; 130: 666-70. 